\title{
Atividades investigativas na formação de professores de ciências: uma aula de campo na Formação Barreiras de Marataízes, ES
}

\author{
Investigative activities in the training of science teachers: \\ a field class in the Barreiras Formation of Marataízes, ES
}

Marcelo Scabelo da Silva ${ }^{1}$. Carlos Roberto Pires Campos ${ }^{2}$

\begin{abstract}
Resumo: A utilização criativa dos espaços não formais pode ajudar a romper o ensino tradicional e proporcionar, por meio de práticas interdisciplinares, no estudo do Sistema Terra, a construção de valores, conhecimentos e habilidades. As aulas de campo favorecem a compreensão da relação entre o espaço vivido e as informações obtidas em sala de aula, permitindo ao aluno maior familiaridade com aspectos físicos e naturais de sua região. O trabalho apresenta uma investigação no campo das metodologias de ensino de Ciências, que ocorreu em um espaço não formal, as falésias de Marataízes, ES. O objetivo foi destacar as aulas de campo como uma metodologia pedagógica que favorece uma leitura crítica do mundo e o trabalho colaborativo. As aulas de campo revelaram a indissociabilidade entre sujeito e objeto da aprendizagem e propiciaram oportunidades para reconhecer as relações homem/ambiente, permitindo a aquisição da consciência das transformações na natureza pelo viés da alfabetização científica.
\end{abstract}

Palavras-chave: Espaços não formais. Aula de campo. Trabalho colaborativo. Alfabetização científica.

\begin{abstract}
The creative use of non-formal settings can help to surpass the traditional teaching in schools, providing, through interdisciplinary, the construction of values, knowledge and skills, for approaching for example the Earth System. Field classes emerge as an important methodology for understanding the relationship between living space and information constructed in the classroom, allowing students to have a better familiarity with physical and natural aspects of their region. This paper reports research in the field of methodology of science teaching, which took place on a non-formal educational setting, the cliffs of Marataízes, Espírito Santo State, in Brazil. The investigation aimed to highlight the field classes as a teaching methodology able to encourage critical reading of the world and collaborative work. The field lessons revealed the inseparability between subject and object of learning and provided opportunities to recognize man/environment relationships, allowing the acquisition of awareness of the transformations in nature through the means of scientific literacy.
\end{abstract}

Keywords: Non formal educational settings. Field class. Collaborative work. Scientific literacy.

\footnotetext{
${ }^{1}$ Instituto Federal de Educação, Ciência e Tecnologia do Espírito Santo (IFES), Vitória, ES, Brasil. E-mail:

$<$ marceloscabelo@gmail.com>.

${ }^{2}$ IFES, Centro de Referência em Formação e em Educação a Distância, Vitória, ES, Brasil.
} 


\section{Introdução}

A educação atual demanda novas metodologias de ensino, novos olhares e formas criativas de abordagem. A discussão de temas relacionados ao exercício da cidadania, ao debate socioambiental, aos direitos humanos, à diversidade, quando transcorrida em grupos, de forma dialógica e interativa, favorece aos participantes a busca de respostas com autonomia. Nesse contexto, ganham tônica especial as atividades colaborativas, aqui compreendidas à luz de Figueiredo (2006), como aquelas em que os participantes trabalham em conjunto, sem distinções hierárquicas, em um esforço coordenado, com vistas a alcançarem um objetivo previamente fixado. Para este autor, quando se desenvolvem atividades colaborativas, as tarefas dos membros componentes do grupo não são estruturadas, o que significa que os papéis são definidos à medida em que a atividade vai transcorrendo. Atividades assim fortalecem a aprendizagem processual, quebram paradigmas e permitem uma maior socialização dos conhecimentos. $\mathrm{O}$ desenvolvimento de atividades colaborativas nas escolas pode gerar resultados diferenciados tanto no campo dos conhecimentos teóricos quanto no campo da formação humana, neste caso, ensejando a construção de valores e atitudes. Algumas dessas atividades, propiciadas pelas intervenções pedagógicas embebidas de intencionalidade e de olhar crítico, ganharam espaço no cotidiano escolar recentemente, sobretudo com relação aos estudos do ambiente. O trabalho com as questões socioambientais demanda a capacidade de superar desafios que surgem diuturnamente no mundo moderno e o reconhecimento, por parte do professor, do seu papel como defensor potencial do ambiente, para também motivar a construção dessa consciência em seus educandos. Como contribuinte a esses desafios, a aula de campo pode vir a favorecer o processo de ensino-aprendizagem nos espaços não formais, promovendo a alfabetização científica e a contextualização dos debates socioambientais.

Dessa perspectiva, a aula de campo se apresenta como uma metodologia pedagógica capaz de proporcionar a interação do estudante com os ambientes externos à escola, isto é, aqueles situados para além dos muros dos espaços formais, os quais podem possibilitar o afloramento de sensações, emoções, dúvidas, reflexões e ensejar o desenvolvimento de investigações criativas (CAMPOS, 2012; SENICIATO; CAVASSAN, 2004, 2008).

Os ambientes costeiros, abordados nos livros de Ciências, tais como praias, dunas, marismas, manguezais, falésias, lagunas, estuários, bem como os processos costeiros, como erosão marinha, movimentos de progradação do mar, são explorados, nas aulas de Ciências e Geografia, da Educação Básica capixaba, de maneira incipiente e acrítica, no tocante às questões inerentes às ações antrópicas na alteração da dinâmica das paisagens litorâneas. Há que se ressaltar a importância dessas questões no Estado do Espírito Santo, onde os principais balneários têm perdido parte significativa de faixas de suas praias com o avanço do oceano. As relações de interdependência homem-natureza, na perspectiva da leitura de mundo e da ciência, são timidamente tratadas e, quando o são, ocorrem de modo desconexo da realidade dos educandos.

Freire (1989) considera relevante o desenvolvimento da capacidade de o ator escolar aprender a ler o mundo e a estabelecer conexões que favoreçam a compreensão da interdependência entre si e o ambiente ao seu redor, com o qual interage e modifica, da mesma forma como o mundo com ele dialoga e o transforma. Dessa maneira, o mundo seria um texto, na perspectiva semiótica, e ler e compreender esse mesmo mundo implicaria a percepção das relações existentes entre texto e contexto. Pela reinvenção, professor e aluno se encontram e 
Atividades investigativas na formação de professores de ciências: ...

se reconhecem como sujeitos intencionados a desvelar e, criticamente, conhecer a realidade, recriando o conhecimento e a refazendo permanentemente (FREIRE, 2002).

A conquista da autonomia política transita por esse viés, demandando do professor a implementação de práticas pedagógicas criativas que intencionem a ampliação da percepção do ambiente e do posicionamento crítico do aprendiz quanto às implicações decorrentes do desenvolvimento científico e tecnológico, sejam aquelas positivas ou negativas.

A alfabetização científica na Educação Básica, por meio do ensino de Ciências Naturais e das Geociências, pode ser compreendida como um processo mediante o qual a linguagem das Ciências Naturais e da Terra adquire sentido, tornando-se uma forma de o ator escolar ampliar seu universo de conhecimento, sua cultura, podendo atuar como ator social. A alfabetização científica constitui o conjunto de conhecimentos que permitem ao sujeito o desempenhar de dois importantes papéis na sociedade, quais sejam: (1) o de facilitar uma leitura do mundo, por parte do indivíduo; e (2) o de entender as necessidades de se transformar o mundo, no intuito de torná-lo um lugar melhor para se viver (CHASSOT, 2014). Fundamentados no exercício desses dois papéis da alfabetização científica, coadunamos com o autor quando este afirma que "vale a pena conhecer mesmo um pouco de Ciência para entender algo do mundo que nos cerca e assim termos facilitadas algumas vivências" (CHASSOT, 2014, p. 64-65).

Nesse contexto, sujeito da aprendizagem e objeto de estudo tornam-se indissociáveis, denunciando a complexidade nas relações entre os elementos de um determinado sistema. Assim, práticas educativas compartimentadas, responsáveis pela fragmentação do conhecimento, precisam ser constantemente discutidas por estimularem a disciplinaridade, que limita o estudante e o impossibilita de enfrentar as complexas relações tecidas entre os elementos naturais e antropossociais (MORIN, 2008). Fica evidente que essa reflexão fortalece as práticas pedagógicas interdisciplinares, tema do qual voltaremos a tratar.

Partindo-se do pressuposto de que a conquista da autonomia política transita pela compreensão das relações sociedade-natureza, numa perspectiva de respeito às limitações do meio ambiente e da conscientização do papel do ser humano em face dos princípios de sustentabilidade e do uso responsável dos recursos naturais, faz-se necessário fortalecer práticas pedagógicas que conduzam a uma leitura de mundo, contribuindo para os processos de formação de mentalidades que visem a um aprendizado contextualizado.

Intencionada a envolver o estudante nessa complexa rede de relações, possibilitandolhe o enfrentamento das incertezas e a busca por proposições que o estimulem a ser crítico e criativo, a aula de campo pode ser capaz de motivar diferentes leituras de mundo, à luz das relações socioculturais que determinam os distintos processos de (re)construção na história das paisagens, sobretudo quando ensejam atividades que favoreçam sua interação com ambiente em face de situações reais (PAVANI, 2013; VIVEIRO; DINIZ, 2009). Isso pode motivá-lo a aprofundar seus saberes, antes desconhecidos ou evitados (RENDEIRO; SANTOS JÚNIOR; TERÁN, 2012), além de levá-lo a compreender a necessidade da (re)descoberta e da articulação das bases do conhecimento tecnocientífico, colaborando, no caminho da sua síntese, para a produção de suas contribuições particulares, propícias a se tornarem públicas e de interesse da coletividade.

As aulas de campo propiciam ao aluno uma nova dimensão dos assuntos abordados nos espaços formais, favorecendo seu protagonismo na (re)construção do saber, por meio da (re)elaboração do aporte teórico veiculado, às vezes, de maneira distorcida, pelos livros didáti- 
cos (SILVA et al., 2015). Nesse sentido, a Formação Barreiras, ambiente natural que bordeja a zona costeira brasileira desde o Estado do Pará até o Estado do Rio de Janeiro e suas escarpas erosivas, as falésias, localizadas no município de Marataízes, sul do Estado do Espírito Santo, surgem como um espaço não formal propício para uma aula de campo, que pode ser conduzida por meio de atividades colaborativas, em grupo, com vistas a uma compreensão crítica do ambiente. Isso, ao favorecerem o binômio interação-dialogia e funcionarem como palco para o desenvolvimento de diferentes leituras de mundo, ensejando um exercício reflexivo na compreensão do espaço e na construção da concepção de lugar.

Assim, este trabalho tem por objetivo destacar o potencial das aulas de campo como uma metodologia pedagógica capaz de favorecer a leitura crítica do mundo, por meio das atividades colaborativas, na formação de professores de ciências, conferindo especial destaque ao debate socioambiental.

\section{Percurso metodológico}

Trata-se de uma investigação qualitativa, teórico-empírica, do tipo estudo de caso, organizada à luz de Lüdke e André (1986), apoiada em observações realizadas pelos pesquisadores, colhidas sistematicamente, em diário de campo. A coleta de dados no campo ocorreu a partir da observação participante, quando os professores-alunos estavam trabalhando, em grupo, na caracterização do ambiente costeiro, isto é, de uma faixa de praia e de uma falésia escarpada de aspecto significativo na paisagem litorânea. As tarefas de caracterização, etapa inicial dos trabalhos em grupo, contaram com procedimentos científicos inerentes ao uso de instrumentos de orientação, posicionamento e medição, como a bússola, o aparelho GPS e a trena, articulados de forma a ensejar atitudes investigativas capazes de propiciar o contato direto e interativo do grupo com a situação de estudo e da interação do grupo entre si, favorecendo a colaboratividade.

Assim, participaram da aula de campo quinze professores-alunos, mestrandos de um Programa de Mestrado em Educação em Ciências e Matemática do Estado do Espírito Santo. Os participantes atuavam em várias áreas do conhecimento, havia professores de ciências, de química, de biologia, de matemática, de geografia, de educação física, de física, de ciências humanas. A diversidade na formação dos professores permitiu momentos ricos de trocas e experiências. Todos atuam na Educação Básica da rede pública municipal e estadual e apresentavam uma média de dez anos de experiência na Educação Básica. Somente os professores biólogos e os geógrafos haviam vivenciado anteriormente aulas de campo em sua formação inicial. Somente dois professores do grupo possuíam a prática de conduzir seus alunos a aulas de campo. A média de idade dos professores participantes da aula de campo variava entre 28 a 50 anos.

Foi utilizado também, para coleta de dados, um checklist desenvolvido por Scudelari et al. (2007) para o estudo dos processos erosivos na zona costeira do Estado do Rio Grande do Norte. Fundamentado nessa proposta, o grupo buscou identificar e caracterizar tanto os aspectos físicos da falésia, como altura, inclinação e ações antrópicas, quanto os processos erosivos relacionados ao escoamento superficial, à associação com a restinga, à percolação da água e à ação erosiva das ondas.

A abordagem pedagógica dos dados foi realizada segundo os pressupostos de um ensino por investigação com vistas à alfabetização científica, conforme os postulados de 
Atividades investigativas na formação de professores de ciências: ...

Sasseron e Carvalho (2008). Foram utilizados alguns critérios para analisar os momentos que favoreceram o processo de alfabetização científica, tomando por base as seguintes categorias: compreensão do problema, hipóteses, comprovação, explicação, raciocínio lógico e prática social. Essas categorias foram escolhidas a partir dos seguintes critérios: permitir uma compreensão do ambiente que se desenvolvia a atividade, permitir identificar ganhos cognitivos, isto é, as atividades deveriam favorecer a construção de novos conhecimentos, partindo-se dos que os professores-alunos já possuíam, favorecendo lhes compreender a ciência, aplicando-a a outros contextos, sobretudo o social. No que se refere ao desenvolvimento de atividades investigativas, em campo, o propósito era favorecer o contato com novas informações advindas do contato com um espaço não formal até então não presente nas práticas pedagógicas dos professores participantes. Para Newman Júnior et al. (2004), as atividades investigativas precisam envolver o uso de evidência, lógica e imaginação na elaboração de explicações acerca da dinâmica do mundo natural e de seus processos.

\section{Contexto da investigação: os espaços não formais, a Formação Barreiras e suas falésias na praia de Marataízes/ES}

Segundo Trilla (2008), os espaços educativos não formais configuram-se como ambientes complementares aos espaços escolares, cujo surgimento está ligado a uma série de fatores sociais, econômicos e tecnológicos, produtores de novas demandas educacionais que suscitaram práticas pedagógicas alternativas e extraescolares. Por estarem intrinsecamente ligados às questões sociais, os conhecimentos construídos em espaços não formais contribuem para construção de uma sociedade autônoma, preparando os cidadãos para vida. O autor defende os espaços não formais como coadjuvantes da formação cidadã, atuando, sobretudo como ajudantes da socialização e da autonomia.

Jacobucci (2008) conceitua um espaço não formal como aquele onde é possível se realizar uma ação educativa e, sobretudo, que seja diferente do espaço escolar. A autora indica duas categorias de espaços não formais, quais sejam: (a) os institucionalizados, como parques ecológicos, museus, centros de ciências, planetários e trilhas interpretativas guiadas, que são devidamente regulamentados e providos de equipe técnica capacitada para o desenvolvimento de atividades relacionadas ao processo educativo; (b) os não institucionalizados, constituídos por ambientes que não proporcionam estruturação institucional, porém, neles é possível fomentar práticas educativas, a exemplo de uma praia, uma praça, sítios arqueológicos, monumentos históricos, entre outros.

Da perspectiva da educação não formal, Gohn (2011) compreende-a socio-historicamente. Para a autora, existem várias potencialidades educativas com a finalidade de formar cidadãos ativos e participantes que fazem da educação não formal um caminho que lhes favorece o contato direto com uma diversidade de aprendizagens articuladas a fatos e fenômenos do cotidiano, na construção de conhecimentos úteis para viver em um contexto planetário globalizado. Essa reflexão dialoga com Trilla (2008), quando este defende a relevância pedagógica dos espaços na formação cidadã.

A região costeira do Espírito Santo constitui-se de muitos ambientes, os quais podem ser tomados como espaços educativos não formais não institucionalizados. A região possui várias lagunas, praias, dunas, falésias, restingas, planícies de maré, manguezais, estuários, até 
paleo-pântanos salinos e depósitos antropogênicos do tipo sambaqui, os quais possuem grande potencial que pode ser explorado por professores e alunos em aulas de campo, com vistas a favorecer não só o aprendizado dos conteúdos escolares, relativos aos ambientes em si, mas, também, uma compreensão holística dos ambientes, da ação humana sobre eles e da resposta que estes ambientes têm dado às ações antrópicas. No sul capixaba, elegemos a Formação Barreiras e suas falésias como espaço não formal para a nossa aula de campo.

A proposta era não somente compreender esse espaço, que foi das primeiras feições geográficas caracterizadas na Carta de Caminha, escrita em 1500, a qual serve de documento de fundação do Brasil, mas também desenvolver uma consciência crítica sobre as ações humanas sobre ele, tais como, agricultura de abacaxi e mandioca, a especulação imobiliária, construção de obras de engenharia, construção de portos e fundação de cidades. As atividades em grupo, em uma aula de campo, se bem planejadas pelos professores, podem levar seus alunos à alfabetização científica, favorecendo aos sujeitos da aprendizagem a vivência em um espaço-tempo que os leva a pensar e a agir de maneira crítico-reflexiva, desenvolvendo competências que contribuam para sua formação escolar e para a consolidação da cidadania. Buscamos compreender a alfabetização científica por meio da sua associação ao processo de aquisição de estruturas conceituais que explicitam princípios científicos subjacentes aos conteúdos de natureza técnico-científica.

\section{As falésias da Formação Barreiras, atividades colaborativas e a alfabetização científica}

A Formação Barreiras, cuja idade pode ser estimada, de acordo com Bezerra, Mello e Suguio (2006), como sendo do período pliocênico ou miocênico, ocorre na região sul do Espírito Santo, nos municípios de Marataízes e Presidente Kennedy. Uma análise inicial feita pelos professores evidenciou que os depósitos sedimentares podem ser representados por níveis descontínuos ou alternados de material friável e mal selecionado. Em campo foi notado que o Barreiras compõe-se de camadas com material conglomerático, contendo seixos de tamanhos variados, angulosos e matriz arenosa. Foi possível perceber, também, leitos areno-argilosos e horizontes lateríticos quando mais próximos da superfície, do horizonte coluvial.

Segundo Nunes (2011), a sedimentação da Formação Barreiras está associada às superfícies "aplainadas", que resultaram da separação da África em relação ao continente sul -americano e sofreram interferência das intensas mudanças climáticas do Cenozóico. Para o autor, distintos ciclos de processos de erosão-deposição produziram a Formação Barreiras a qual sofreu, também, influências de eventos neotectônicos.

Da perspectiva geomorfológica, é possível apontar que três unidades de relevo constituem o território capixaba: (1) os tabuleiros neogênicos da Formação Barreiras; (2) os afloramentos e promontórios cristalinos pré-cambrianos; e (3) as planícies flúvio-marinhas quaternárias (ALBINO; GIRARDI; NASCIMENTO, 2006). No tocante aos tabuleiros da Formação Barreiras, trata-se de uma unidade geomorfológica que se alonga por todo litoral, configurando-se na paisagem em forma de falésias vivas, falésias mortas ou terraços de abrasão marinha, expostos na maré baixa. As falésias vivas (Figura 1) seriam aquelas ainda em processo de erosão pela ação marinha. Já as falésias mortas (Figura 2) não sofrem mais o processo erosivo, já evidenciam um recuo do mar com abertura de faixa de restinga. 
Atividades investigativas na formação de professores de ciências: ...

Figura 1. Falésia viva sofrendo ação erosiva do mar, evidenciando horizontes e terraço de abrasão marinha

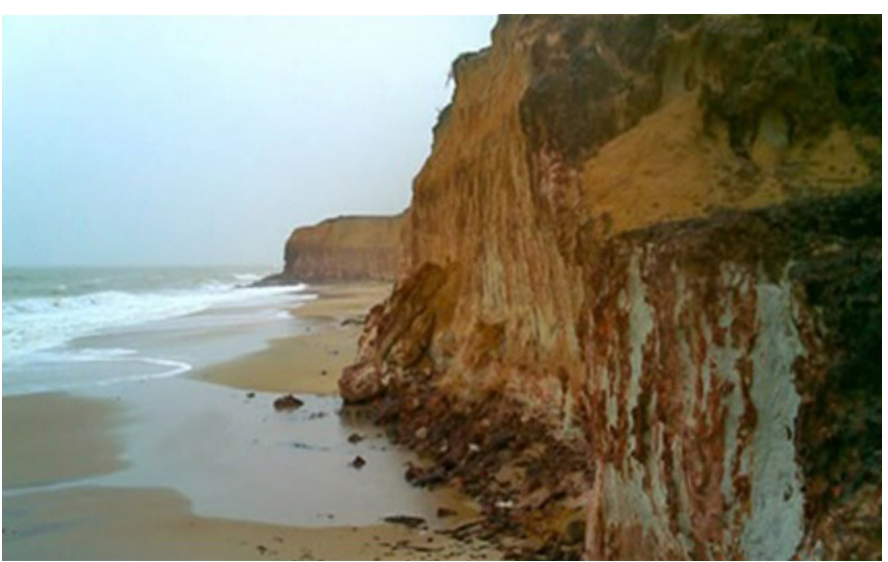

Fonte: Banco de dados dos autores

Ainda de acordo com Albino, Girardi e Nascimento (2006), a Formação Barreiras estende-se desde a região amazônica até o Estado do Rio de Janeiro e, em terras capixabas, detém um papel de destaque nos ambientes costeiros, principalmente naqueles compreendidos entre a Baía do Espírito Santo e a margem norte da desembocadura do rio Itabapoana. A ação combinada das correntes marinhas, dos rios e dos ventos pode influenciar na fisionomia dessa unidade geomorfológica (INSTITUTO JONES DOS SANTOS NEVES, 2012).

Figura 2. Falésia morta evidenciando faixa de restinga e paleovale à direita. Marataízes, ES

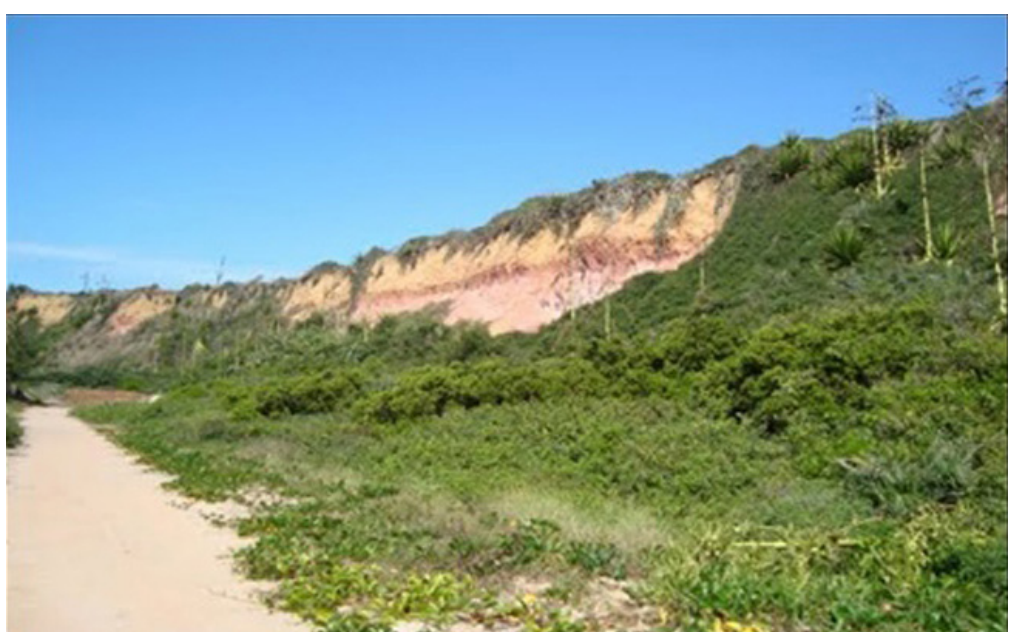

Fonte: Banco de dados dos autores 
Incorporar esses espaços não formais, com vistas à potencialização de um processo ensino-aprendizagem fundado na perspectiva da alfabetização científica, significa, em nosso contexto de educadores-pesquisadores, trazer para o centro do palco uma dinâmica capaz de fomentar um ato educativo crítico-reflexivo, no que concerne ao olhar questionador sobre os ambientes costeiros e sua importância para a vida humana. Isto posto, justificamos a proposição de uma formação continuada de professores, por meio de uma aula de campo nas falésias do município de Marataízes (ES), embasados nos pressupostos de Campos (2012) quanto à construção da aprendizagem de conceitos científicos que envolvam conteúdos interdisciplinares, bem como nas proposições de Viveiro e Diniz (2009), concernentes ao contato direto que o educando realiza com o ambiente, em face das variadas possibilidades de interação como protagonista na construção do seu próprio conhecimento. Comunga dessa reflexão Piranha (2015, p. 30), para quem o estudo do Sistema Terra demanda o desprendimento das práticas e métodos "que compõem modelos de ensino e aprendizagem tradicionais". Para a autora, as barreiras disciplinares desaparecem quando existe contato entre os diversos conhecimentos. Reflexões assim fortalecem o caráter interdisciplinar das aulas de campo. Segundo Piranha (2015, p. 30), "A ciência do Sistema Terra, tal qual se revela, constitui franco contexto interdisciplinar. Nela operam-se inter-relações, interações, interferências, complementaridades, oposições e interdependências". É nessa dimensão que os trabalhos de campo devem ocorrer.

Além disso, uma aula de campo em um espaço não formal demanda um trabalho em equipe, mobilizando o corpo administrativo, o pedagógico, os docentes e discentes, rompendo com a rotina da escola. Organizar uma aula de campo, tomando-a como uma metodologia pedagógica de relevância cultural e social, significa inovar o processo de ensino e de aprendizagem, ultrapassando as dimensões cognitivas e afetivas. Aumenta-se a sociabilidade, a autoestima, melhora-se a capacidade de trabalho em grupo e até o relacionamento entre professores e alunos. É possível também ampliar e construir uma concepção pedagógica crítica do ambiente (COMPIANI, 2015), colocando em jogo a qualificação do lugar da escola e de seus atores escolares, como por exemplo, neste artigo, buscar a compreensão das inter-relações entre os ambientes costeiros e o avanço da urbanização.

Compiani e Carneiro (1993) discutem acerca do objetivo das excursões para o ensino de Geologia, neste artigo, tomadas como aulas de campo, com a intenção de permitir os participantes a se apropriarem de um instrumental teórico-metodológico profícuo na exploração dessas excursões, como metodologia pedagógica. Os autores definem os papéis didáticos das aulas de campo como funções assumidas, no cerne do processo ensino-aprendizagem, intencionalmente ou não, as quais podem ajudar a desempenhar determinado sentido no alcance dos objetivos didáticos. Em campo, os alunos desenvolvem um sentido integrador na percepção da totalidade dos processos naturais, reconhecendo a inseparabilidade homem-ambiente ao analisarem as transformações da paisagem. Ao observar dessa forma, o ser humano torna-se protagonista dos fenômenos naturais e, em face das modificações por ele promovidas, o "fazer geológico”, em campo, é que legitima os estudos de Geografia e de Ciências Ambientais. Um dos papéis didáticos das aulas de campo pode ser o desenvolvimento da habilidade de observação dos fenômenos de modo a compreender um problema, construir uma concepção pedagógica sobre ele e participar do debate socioambiental.

Tal processo implica a realização de uma prática de campo favorecedora da síntese do conhecimento, cuja trajetória possa ser mediada pelas teorias científicas, pela natureza e 
Atividades investigativas na formação de professores de ciências: ...

pelo objeto de estudo das Ciências. Isso significa que as aulas de campo poderão se constituir em uma produtiva metodologia para aproximar o aluno da prática do cientista. Em campo, o aluno pode assumir uma atitude investigativa, abarcando a complexidade, os princípios e os métodos científicos, valorizando a vivência, a criticidade e se sentindo motivado (COMPIANI; CARNEIRO, 1993).

Embasados nesses pressupostos, Compiani e Carneiro (1993) propuseram uma categorização formal para as aulas de campo, considerando seus papéis didáticos. Importa destacar que não se trata de um modelo padrão de enquadramento, mas de um "exercício teórico" ou de uma tentativa de generalização de modo a orientar as observações ajudando a interpretar as potencialidades das práticas de campo.

Para a sistematização dessas categorias, Compiani e Carneiro (1993) elencaram cinco parâmetros, os quais subsidiaram a categorização, quais sejam, os objetivos da prática de campo e o seu grau de influência, dando ênfase à participação e ao desempenho específico dos alunos; a visão de ensino, distinguindo-se as práticas de campo que apresentam aspectos típicos do ensino tradicional das práticas formativas; os modelos científicos em voga, segundo os quais, uma prática de campo pode restringir-se à aceitação e à preservação de um dado modelo, ou, contrariamente, a sua aceitação e a seu questionamento, no decorrer do processo de aprendizagem, quando emergem incertezas provocadoras de novas investigações; o método de ensino e a relação professor-aluno; a lógica predominante na aprendizagem, concernente tanto à "lógica da Ciência" quanto à "lógica do aprendiz".

Estas categorias e papéis didáticos de que as aulas de campo podem se revestir configuram-se como pedra basilar neste trabalho, tendo em vista que um de seus objetivos foi desenvolver uma formação continuada de professores com vistas a propiciar uma leitura crítica de mundo, construir uma concepção pedagógica do lugar e levar seus participantes à alfabetização científica, tanto a partir da perspectiva da "lógica da Ciência" quanto da sua própria lógica", no transcorrer da prática de campo.

Tendo como ponto de partida a possibilidade de desenvolver uma aula de campo, para formação continuada de docentes nas falésias do sul capixaba, buscamos valorizar os aspectos das atividades colaborativas nos processos de raciocínio e na construção de valores humanos (SENICIATO; CAVASSAN, 2004), considerando as experiências sensoriais que podem ser desenvolvidas, como fator essencial na apropriação das características ambientais que perpassam os diferentes momentos em que o elemento humano interage com o ambiente. Articular a teoria com a prática consciente tornam as aulas de campo um atrativo integrador do conhecimento, transformando o estudante em um sujeito crítico para analisar um mesmo objeto de estudo, a partir das contribuições de várias disciplinas (SILVA; SILVA; VAREJÃO, 2010).

\section{Resultados}

Ao longo da rodovia ES-060, sentido Marataízes-Presidente Kennedy, existem diversas encostas pertencentes à Formação Barreiras já bastante modificadas pela ação antrópica, tanto por consequência da expansão imobiliária quanto pela interferência da malha rodoviária. A falésia escolhida para a realização da aula de campo localiza-se nas coordenadas geográficas $21^{\circ} 08^{\prime} 51^{\prime \prime S}$ (latitude); e 4053'10"O (longitude). As discussões em campo iniciaram-se com 
debate do grupo acerca das potencialidades pedagógicas daquele ambiente com vistas ao processo de alfabetização científica. Isto é, o que podemos aprender com aquele ambiente para, em momento posterior, conduzirmos nossos alunos àquele espaço e desenvolvermos uma prática pedagógica? O grupo de professores-alunos buscou articular diversos conceitos e procedimentos inerentes aos ambientes costeiros, elencando conhecimentos capazes de favorecer uma leitura que contivesse um olhar sobre o relevo, sua constituição, sua cobertura vegetal, o movimento do mar, a descarga de sedimentos que os rios e lagunas despejam nas proximidades entre outros, de modo a organizar elementos que levariam à participação dos alunos no seu próprio processo de aprendizagem. No sul do Espírito Santo, a cidade de Marataízes e a localidade de Boa Vista do Sul foram assentadas sobre a faixa de restinga que se abriu após a retrogradação do mar, com a ampliação da faixa continental. Com o crescimento a partir da década de 1970, a ocupação urbana em Marataízes começou a avançar sobre as colinas da Formação Barreiras. Esse foi o primeiro tema de discussão.

Escolhido, pois, o ponto para o desenvolvimento da intervenção pedagógica no ambiente, os professores-alunos foram divididos em grupos. Após a passagem pelos dois pontos de checagem de georreferenciamento, o subgrupo constituído pelos autores desse artigo elegeu, e delimitou, um ponto com área aproximada de $200 \mathrm{~m}^{2}$, com o objetivo de identificar e descrever, com simplicidade, características geológicas e geomorfológicas, dando ênfase especial às relações antrópicas do ambiente. Uma primeira característica foi a alternância entre falésias vivas e mortas associadas a uma estreita faixa de praia. Em alguns trechos, onde a encosta apresenta uma declividade mais acentuada, o grupo constatou a existência de um paleovale (NUNES, 2011), cuja vegetação continha espécies características das matas de restinga. Foi observada também uma certa vulnerabilidade dessa área em relação à enxurrada vertical de sedimentos e de drenagem de águas.

$\mathrm{Na}$ interpretação da falésia viva, o grupo identificou suas camadas, sendo que mais próxima à superfície, a camada era formada por matéria orgânica e solo inconsolidado, com presença de bioturbação, sedimentos de coloração mais escura, evidenciando forte intemperismo. $\mathrm{Na}$ camada inferior, havia a predominância de sedimentos areno-argilosos e presença de seixos grandes, angulosos e arredondados, de coloração branco-avermelhada. Na camada subsequente, constatou-se predominância de sedimentos argilosos mais compactados, de granulação fina, coloração laranja-avermelhada, possivelmente devido à presença de hidróxido de ferro, enquanto na camada que dialoga diretamente com as ondas, verificou-se a evidência do embasamento rochoso, localizado na parte basal da falésia, formado por arenitos ferruginosos ou laterita, intemperizados pelas águas do Atlântico.

$\mathrm{Na}$ base da falésia ativa, em contato erosivo com o mar e as ondas, encontra-se um terraço de abrasão marinha (ALBINO, 1999 apud ALBINO; GIRARDI; NASCIMENTO, 2006) constituído por arenito ferruginoso ou laterita. Da parte superior da falésia até a base, há um depósito de material coluvionar, o que sugere uma interferência tanto da erosão eólica quanto da plúvio-marinha sobre a encosta. Nessa parte da praia, atividades erosivas se apresentam muito intensas, vez que, além da constatação do movimento de massa, também se observou a intemperização das rochas.

Percorridos alguns metros, no sentido nordeste-sudoeste, o grupo passou a interagir junto ao cordão arenoso (Figura 3), onde se manifesta uma biota de restinga associada a uma falésia morta. Nesse segundo ponto de parada, diversos conceitos acerca da Biologia, da Química 
e da Geografia foram debatidos, produzindo reflexões criativas quanto à relevância das aulas de campo em ambientes costeiros. Neste momento, foi possível evidenciar o caráter interdisciplinar das aulas de campo para conhecimento do Sistema Terra (PIRANHA, 2015). Em um dos momentos mais significativos, os dois professores da área de química do grupo compartilharam de seus conhecimentos com os demais, demonstrando a manipulação de reagentes em amostras de rochas intemperizadas (Figura 4), tornando, assim, o campo, um chamariz que contribuiu substancialmente para a compreensão dos fenômenos relacionados ao intemperismo químico e sua ação sobre o solo e as rochas.

Figura 3. Interação junto ao cordão arenoso

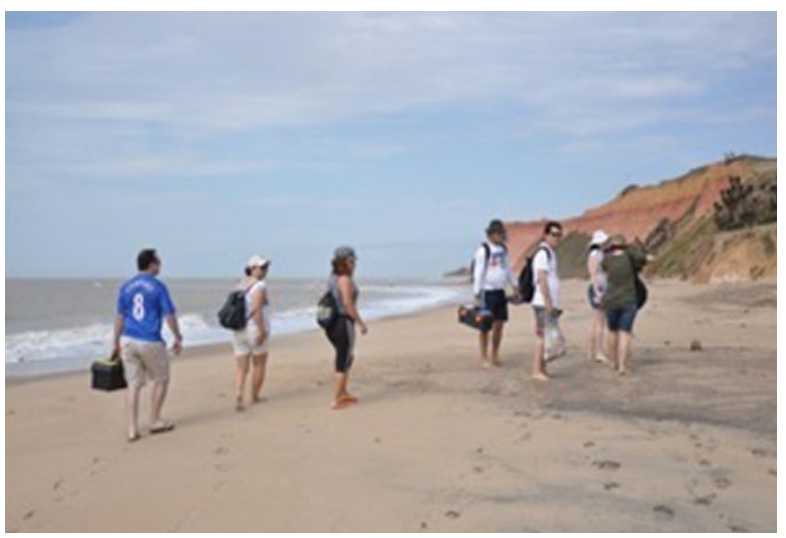

Fonte: Banco de dados dos autores

Figura 4. Manipulação de reagentes em amostras

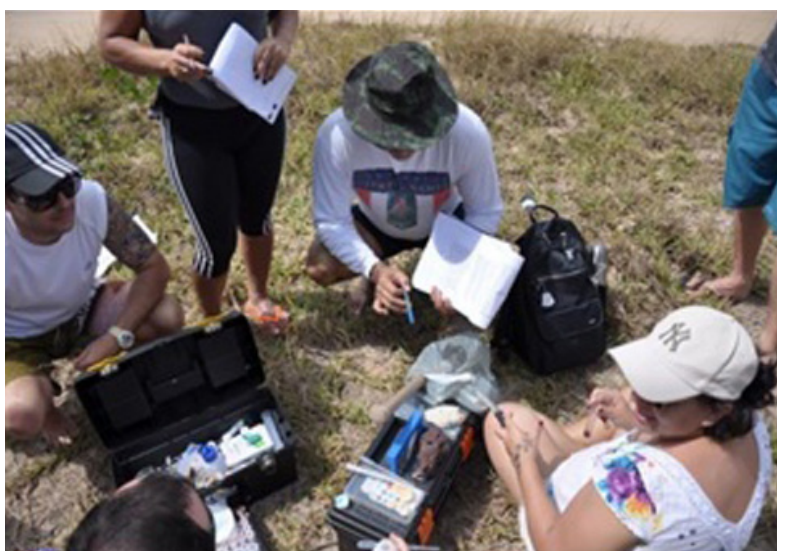

Fonte: Banco de dados dos autores 
É esse intercâmbio conceitual-procedimental que legitima os princípios da alfabetização científica e consubstancia a proposição da ciência como facilitadora das contribuições do ser humano para o controle e a prevenção das transformações na natureza, propiciando melhorias na qualidade de vida (CHASSOT, 2003, 2014).

Em um segundo momento do campo, o grupo passou a trabalhar com outros domínios do conhecimento, mantendo a perspectiva interdisciplinar. A partir da bússola, do aparelho GPS, da trena e do diário de campo, a equipe, formada por cinco integrantes, elegeu uma encosta de falésia morta, com face direcionada para o sudeste, latitude de $21^{\circ} 08^{\prime} 53^{\prime \prime}$ S e longitude de $40^{\circ} 53^{\prime} 12^{\prime \prime} \mathrm{O}$, para a identificação e caracterização de uma pequena porção do ambiente em estudo. A utilização proficiente de ferramentas para a aula de campo indica o domínio da alfabetização científica funcional, a qual demanda a adoção de métodos e técnicas apropriadas para a leitura do ambiente costeiro e para a compreensão pedagógica do lugar/ambiente (COMPIANI, 2015) onde se constrói uma atividade educativa.

Além de ensejar um trabalho interdisciplinar, a aula de campo proporciona o contato com a natureza e os objetos de estudo in loco, incentivando a leitura do mundo no âmago da perspectiva sociocultural. Nesse ponto, há o diálogo com dois dos papéis didáticos apontados por Compiani e Carneiro (1993), quando os professores-alunos em formação se comportaram como cientistas na produção do conhecimento e quando refletiram sobre os modelos científicos em voga, ao questionarem a forma como os livros didáticos são organizados, os artigos de divulgação científica entre outros.

Ao realizarem a tarefa de caracterizar uma feição da falésia escarpada (SCUDELARI et al., 2007), a qual apresentava as seguintes características: falésia morta, recuada da praia, com cerca de $20 \mathrm{~m}$ de altura e perfil de talude levemente inclinado, os professores-alunos atuaram como geólogos em campo, produzindo conhecimentos. Ao detalharem que a vegetação se distribui irregularmente do topo à base, com maior densidade herbácea e arbustiva na face da encosta, os professores-alunos atuaram como biólogos. Ao detalharem que o uso da falésia se restringia ao acesso à praia e que nela não havia edificações no topo, havia ausência de escoamento superficial descontrolado na face da falésia, uma vez que a vegetação de restinga exerce controle sobre a encosta e evita sistemas de fratura na planície que cobre o topo da falésia, os participantes da prática de campo comportaram-se como geógrafos na leitura do espaço ordenado e transformado pelo homem para seu uso. Além desses dois papéis didáticos, outros podem se evidenciados, sobretudo o que relaciona às aulas de campo ao método de ensino com ênfase na relação professor-aluno.

\section{Discussão}

Para Chassot (2003), as explicações científicas podem estar em diversos locais e, para entender o mundo em que vivemos, ao mesmo tempo em que compreendemos os fenômenos nele existentes, precisamos dominá-las adequadamente. A ciência, por ser uma forma de linguagem, tentará explicar parte destes acontecimentos na natureza, portanto, precisamos dominar essa linguagem. Para o autor, a alfabetização científica é uma das dimensões que servirá para privilegiar alternativas na educação que busquem contemplar condições para que alunos e alunas compreendam as manifestações do universo, corrigindo ensinamentos truncados. Este mesmo 
Atividades investigativas na formação de professores de ciências: ...

autor defende que a escola fará alfabetização científica quando conseguir instrumentalizar seus atores escolares para utilizar os conhecimentos científicos adquiridos na resolução de problemas do cotidiano e tomar decisões responsáveis, de modo a socializar a ideia de que a ciência tanto pode contribuir para a melhoria das condições de vida da população, quanto pode gerar efeitos ruins para o ser humano e para o ambiente.

A leitura geográfica do lugar, realizada pelos professores-alunos na aula de campo focou na descrição das feições dos ambientes costeiros e na discussão dos problemas decorrentes das relações sociais advindas da ocupação do espaço e dos modos agressivos em sua utilização. A proposta era compreender melhor as mudanças pelas quais o lugar passou em virtude dos processos histórico-geográficos (COMPIANI, 2015). Isso, com a intenção de avançar na compreensão de que, desde o início da colonização brasileira, a Formação Barreiras vem servindo de palco para a exploração das atividades econômicas. Corrobora essa hipótese a reflexão iniciada por um dos professores que participaram da aula de campo, o qual lembrou que a ocupação do Brasil ocorreu, até a metade do século XVIII, nos ambientes costeiros.

As colinas de topo achatado da Formação Barreiras têm recebido, ao longo de 500 anos de ocupação, lavouras de mandioca, plantações de cana de açúcar, de abacaxi, sofrem com a retirada de seus recursos minerais para a construção civil, tiveram sua cobertura vegetal devastada para dar lugar a atividades pastoris entre outras ações não menos lesivas. Levar os professores alunos a um avanço no desenvolvimento dos níveis cognitivos, construindo-lhes novas arquiteturas informativas, pelo estímulo à reflexão e ao debate junto aos pares, a partir de questionamentos que transcenderam a identificação dos problemas, foi, pois, o móbil dessa atividade investigativa. Compreender que a Terra, o Mundo e o Lugar funcionam como um grande sistema integrado, dinâmico e aberto, onde convivem distintos fenômenos da matéria (naturais e sociais), "subsistemas, ciclos e o mais significativo fenômeno que é a esfera social" (COMPIANI, 2015, p. 56) foi o grande desafio dessa formação continuada.

Para Sasseron e Carvalho (2008, p. 72), o ensino de Ciências não pode se restringir à "transmissão de conhecimentos, mas deve mostrar aos alunos a natureza da ciência e a prática científica e, sempre que possível, explorar as relações existentes entre ciência/tecnologia/sociedade." As autoras apresentam pressupostos teóricos importantes que podem ser utilizados para indicar algumas ações e habilidades produzidas para resolução de um problema as quais podem resultar em um processo de alfabetização científica.

Apresentamos a seguir as categorias elencadas por Sasseron e Carvalho (2008), adaptadas por Leonor (2013), e os momentos colhidos na formação continuada, os quais evidenciam avanços na alfabetização científica dos participantes com relação à leitura do ambiente costeiro (Quadro 1), com foco nas práticas sociais (GOHN, 2011; COMPIANI, 2015).

No que se refere ao desenvolvimento de habilidades evidenciadoras da alfabetização científica, para facilitar a leitura didática, apresentamos, a seguir, um quadro, e posteriormente, uma discussão. A escolha dessas categorias de alfabetização científica buscou propor um diálogo com alguns dos papéis didáticos das aulas de campo apontados por Compiani e Carneiro (1993). Assim sendo, quanto à importância dos objetivos da prática de campo e o seu grau de influência, articulamos à categoria “Compreensão do problema”, pois está relacionado ao desempenho dos alunos na prática de campo, isto é, ao participar com acuidade, o aluno poderá compreender criticamente o problema. Para a categoria "a visão de ensino" (COMPIANI; CARNEIRO, 1993), buscamos diálogo com a categoria “comprovação do problema”, vez que ao efetuar uma 
constatação em campo, rompe-se com as aulas tradicionais, favorecendo-se práticas criativas, participativas e interdisciplinares (PIRANHA, 2015). Para a categoria de Compiani e Carneiro (1993) "os modelos científicos em voga", elegemos as categorias "justificativa e raciocínio lógico" (LEONOR, 2013), tendo em vista que a prática de campo conduziu os participantes a questionamentos de postulados levando-os a incertezas provocadoras de novas investigações. Articulamos a categoria "a lógica predominante na aprendizagem” (COMPIANI; CARNEIRO, 1993), com a categoria "Prática social” (LEONOR, 2013), pois propõe um diálogo entre a lógica da ciência com a de quem aprende.

Quadro 1. Análise das categorias de alfabetização científica da atividade desenvolvida

\begin{tabular}{|l|l|}
\hline $\begin{array}{l}\text { Categorias da } \\
\text { alfabetização } \\
\text { científica }\end{array}$ & \multicolumn{1}{c|}{\begin{tabular}{c}
\multicolumn{1}{c|}{ Episódios e recortes de falas } \\
Compreensão das atividades desenvolvidas
\end{tabular}} \\
\hline $\begin{array}{l}\text { Compreensão } \\
\text { do problema }\end{array}$ & $\begin{array}{l}\text { Quando os participantes identificaram, no espaço em que iriam intervir, a falésia } \\
\text { morta ou recuada, reconhecendo a vegetação que se formou no pós-praia. Quando } \\
\text { os alunos perceberam a relevância de estudar as relações entre homem e ambiente } \\
\text { costeiro. Quando os participantes se questionaram se o mar sempre esteve nesse } \\
\text { nível e se houve mudanças, quais os efeitos?. }\end{array}$ \\
\hline $\begin{array}{l}\text { Comprovação } \\
\text { do problema }\end{array}$ & $\begin{array}{l}\text { Foi identificada mudança na cor nos horizontes da falésia, foram apontados } \\
\text { alguns paleoníveis. Foram reconhecidas carapaças ferruginosas evidenciadoras de } \\
\text { atividades pretéritas advindas do nível do mar diferente do de hoje. Uma discussão } \\
\text { em campo indicou uma queda na produção pesqueira do estado, fato que pode ser } \\
\text { decorrente das alterações antrópicas provocadas nos ambientes costeiros. }\end{array}$ \\
\hline Justificativa & $\begin{array}{l}\text { A Análise química do arenito ferruginoso evidenciou a presença de hidróxido de } \\
\text { ferro e indicou a presença de outros minerais formados pela ação do mar. Foi } \\
\text { identificada a percolação da água ferruginosa nas camadas da falésia. Com relação } \\
\text { à queda da produção pesqueira, mudanças biofísicas nos ambientes e nos oceanos, } \\
\text { provocados pelas atividades humanas, têm impactado diretamente sobre as formas } \\
\text { de sobrevivência de muitas comunidades de pescadores. As ações antrópicas têm } \\
\text { tornado vulneráveis tais comunidades, sobretudo no município de Marataízes por } \\
\text { sua tradição na produção de pescado. }\end{array}$ \\
\hline Prática social & $\begin{array}{l}\text { A partir do observado, foi possível concluir acerca da dinâmica costeira e as inter- } \\
\text { ferências antrópicas sobre os frágeis ambientes. Foi possível compreender que as } \\
\text { mudanças biofísicas interferem na produção pesqueira. }\end{array}$ \\
\hline $\begin{array}{l}\text { Raciocínio } \\
\text { lógico } \\
\text { constras de engenharo de casas sobre as falésias, mudanças na paisagem provocam destruição } \\
\text { dos ambientes e influenciam na dinâmica costeira e na economia local. Importância } \\
\text { da preservação ambiental. }\end{array}$ \\
\hline
\end{tabular}

Fonte: Elaborado pelos autores baseado em Leonor (2013).

É possível, ainda, articular as categorias desenvolvidas por Sasseron e Carvalho (2008), adaptadas por Leonor (2013), apropriadas nesse trabalho, com os objetivos da aprendizagem 
de uma aula de campo indicados por Compiani e Carneiro (1993). Essa interlocução busca dar sentido às práticas de campo na medida em que, ao citar um momento da aula de campo, observado no diário de campo, conseguimos indicar qual categoria da alfabetização científica foi atingida e o seu respectivo objetivo de aprendizagem.

Assim, quando o participante demonstrou compreender o problema em estudo, ele atingiu o objetivo de aprendizagem relacionada ao aproveitamento dos conhecimentos prévios. Quando os participantes conseguiram comprovar que realmente havia um problema a ser estudado, quando conseguiram reconhecer as feições da falésia e fenômenos da natureza que a formaram, houve uma apropriação dos conhecimentos. Quando os professores-alunos puseram em reflexão o problema, eles demonstraram seu potencial de formular dúvidas e questões sobre o tema em estudo. Ao atingirem o objetivo de aprendizagem relacionado à estruturação de sínteses e à elaboração de conhecimentos, os alunos demonstraram seu raciocínio lógico e ao desenvolverem práticas, atitudes e valores com relação ao ambiente eles conseguiram alcançar a categoria prática social. Essa seria a categoria mais importante pois, segundo Compiani (2015, p. 56), pouco sabemos sobre o papel da esfera social como parte do processo de desenvolvimento histórico da Terra, precisando ficarem "manifestas as profundas relações entre social e econômico, ética e política, ciência e técnica e o entorno social e natural, relações estas que devem ser historicamente contextualizadas."

A identificação de pontos para o estudo, a caracterização física do ambiente, a descrição dos processos erosivos ali presentes, a leitura dos eventos geológicos, a compreensão crítica de que milhares de anos de história geológica foram impactados por ações antrópicas integram os fatores que foram considerados para indicar o avanço na alfabetização científica. Levar esses temas para a sala de aula significa ensejar aos educandos uma reflexão avaliativa acerca dos efeitos da ação antrópica, e da própria ciência, nos ambientes costeiros (COMPIANI, 2015). A exploração de argilominerais, a construção de obras de engenharia, a urbanização da orla, tudo isso exige dos alunos um posicionamento político quanto às consequências do desenvolvimento científico e tecnológico (CHASSOT, 2003), o qual poderá facultar-lhes a capacidade de contribuir para a prevenção de possíveis desequilíbrios em ambientes costeiros. O sonho de construir uma casa no topo da falésia, para abrir a janela de manhã e contemplar o mar, não pode ser materializado sem se questionar até que ponto tal ato pode impactar todo o ambiente. Estas questões dialogam com as duas categorias iniciais, quais sejam, a organização das informações e a comprovação das informações anteriormente levantadas.

A educação científica tem por objetivo oferecer uma formação para que o professor aprenda temas contextualizados com a realidade na qual ele está inserido, dotando-o não só da dimensão conceitual, mas também da ético-política, em defesa dos direitos humanos e da sustentabilidade. Comungamos desses pressupostos quando destacamos a relevância de uma alfabetização científica na formação continuada de professores, de modo a construir a criticidade e o potencial de avaliação dos objetos que são comercializados e socializados pela mídia. Os professores participantes da aula de campo conseguiram justificar suas hipóteses na compreensão dos problemas indicados quando perceberam que a especulação imobiliária no sul do Estado do Espírito Santo alarga seus tentáculos oferecendo às pessoas condomínios com praias privativas, em faixas de restinga, em vales que funcionam como rede de drenagem da Formação Barreiras. Até há dez anos não havia motivações para preservar estes ambientes. É recente o despertar para a consciência ambiental. O próprio DER destruiu muitos desses vales para a construção 
de obras de engenharia, pavimentando rodovias para escoamento da produção agrícola. Estes temas, quando levados para o debate em sala de aula, demandam o posicionamento político e a tomada de decisão, pois esses problemas interferem diretamente na vida de todos.

Esta é, portanto, a razão de ser das atividades investigativas, isto é, levar o aluno a refletir, a discutir, a explicar, a assumir um posicionamento e não apenas se limitar à manipulação de objetos e à observação dos fenômenos do ambiente. Isso significa reconhecer feições e fenômenos da natureza, significa questionar a relação homem e ambiente e, sobretudo, desenvolver habilidades, atitudes e valores com relação ao ambiente capixaba. Ao aprender procedimentos para conhecimento técnico do ambiente, com a manipulação de GPS, de trenas, de altímetros, entre outros, o aluno aprende conceitos, mas a investigação torna-se mais rica quando ultrapassa este limite e alcança níveis de compreensão mais elaborados, como por exemplo, a compreensão crítica do problema que a destruição dos ecossistemas costeiros representa para um estado de tradição marítima, caso do Espírito Santo. Esta questão levou à formulação de hipóteses, levou à curiosidade científica, ensejou discussões. Foi possível problematizar conhecimentos do cotidiano de modo a alcançar a passagem para a consciência epistemológica acerca da questão. Muitos dos participantes da aula de campo questionaram a queda na produção de pescado nos últimos cinco anos. Após a aula de campo, os participantes já defendiam o postulado que, com a alteração na dinâmica costeira e a construção urbana em áreas de domínio do mar, provocando alteração da paisagem, houve grandes impactos na economia do local, sobretudo com relação à pesca e à agricultura. Os participantes compreenderam que as ações antrópicas podem ter impactado negativamente a produção pesqueira. Essas explicações contribuíram para a efetivação da atividade investigativa. Ao apresentarem as respostas ao problema inicial, a partir dos dados obtidos e analisados em campo, os participantes da aula de campo fecharam o ciclo e compreenderam a relevância das atividades investigativas no ensino de ciências (ZOMPERO; LABURU, 2011).

Por último, importa destacar que uma pessoa alfabetizada cientificamente, um professor da educação básica alfabetizado cientificamente, adota condutas que o caracterizam como pessoa cientificamente instruída, com o quê se tornará mais objetivo e aberto a questionar o conhecimento que o cerca. Esse professor conseguirá mudanças culturais, mudanças de valores e terá atitudes políticas em relação a tudo o que a mídia socializa. Nesse momento, evidenciamos mais uma vez, um dos papéis didáticos do trabalho de campo. Ser alfabetizado cientificamente significa dotar-se de uma compreensão geral dos fenômenos naturais. Significa, ainda que, de maneira basilar, aprender a questionar os conhecimentos científicos e tecnológicos disseminados na mídia e se posicionar em face de temas relacionados ao debate socioambiental.

\section{Considerações finais}

Apropriar-se da aula de campo como metodologia de ensino de Ciências, buscando promover a articulação dos conteúdos curriculares, em consonância com o desenvolvimento de investigações científicas interdisciplinares, é uma forma de propiciar ao estudante espaços-tempos que permitam seu reconhecimento como partícipe das transformações das paisagens, ao mesmo tempo em que constrói seu próprio processo de aprendizagem, saindo de uma postura passiva e se convertendo no protagonista dessa construção. Atividades dessa natureza permitem ao aluno manipular diferentes instrumentos em campo, a desenvolver procedimentos nas atividades 
Atividades investigativas na formação de professores de ciências: ...

investigativas, na busca pela percepção-ação de seu objeto de estudo. Nesse contexto, articular instrumentos de posicionamento, orientação, medida e de registro, como o aparelho GPS, a bússola, a trena e o diário de campo, significa harmonizar o arcabouço conceitual com os métodos e técnicas que favoreçam o desenvolvimento da prática e da experimentação interdisciplinar em espaços de educação não formal. Dessa forma, do ensejo à consecução de objetivos, os atores escolares extrapolarão a sala de aula, os livros didáticos e alcançarão o debate socioambiental.

Como uma prática pedagógica estimuladora de novas leituras de mundo, a aula de campo pode fomentar situações potencializadoras da alfabetização científica e, especificamente em ambientes costeiros, torna-se necessária, na medida em que inúmeras demandas vêm exigindo de todos nós a articulação de saberes das mais diversas áreas do conhecimento científico, seja para a percepção-ação concernente ao espaço educativo não formal aqui proposto ou para qualquer outra ocasião que requisite uma tomada de decisão no contexto local-regional-planetário. Enfim, não bastava aprender a dinâmica costeira, mas compreender como a ação antrópica nela interfere e como podemos trazer esses temas para nossas salas de aula. É possível destacar que uma aula de campo pode propiciar trocas interculturais e uma valorização do trabalho em equipe, capacitando os participantes para uma tomada de decisão que demande conhecimentos para participação política nas questões inerentes à relação homem-ambiente. Se alcançar esses objetivos, a aula de campo, por meio da pedagogia crítica do lugar/ambiente, conseguirá desconstruir o modo escolar da disciplinaridade e dos métodos tradicionais e introduzir o papel do lugar nos currículos escolares (COMPIANI, 2015).

\section{Referências}

ALBINO, J.; GIRARDI, G.; NASCIMENTO, K. A. Espírito Santo. In: MUEHE, D. (Org.). Erosão e progradação do litoral brasileiro. Brasília: MMA, 2006. p. 229-264.

BEZERRA, F. H. R.; MELLO, C. L.; SUGUIO, K. A Formação Barreiras: recentes avanços e antigas questões. Geologia USP, Série Científica, São Paulo, v. 6, n. 2, 2006.

CAMPOS, C. R. P. A saída a campo como estratégia de ensino de ciências: reflexões iniciais. Revista Eletrônica Sala de Aula em Foco, Vitória, v. 1, n. 2, p. 25-30, 2012.

CHASSOT, A. Alfabetização científica: questões e desafios para a educação. 6. ed. Ijuí: Unijuí, 2014.

- Alfabetização científica: uma possibilidade para a inclusão social. Revista Brasileira de Educação, Rio de Janeiro, n. 22, p. 89-100, jan./abr. 2003.

COMPIANI, M.; CARNEIRO, C. D. R. Os papéis didáticos das excursões geológicas. Enseñanza de las Ciencias de la Tierra, Alicante, v. 1, n. 2, 1993, p. 90-97.

COMPIANI, M. Por uma pedagogia crítica do lugar/ambiente no ensino de geociências e na Educação Ambiental. In: BACCI, D. L. C (Org.). Geociências e Educação Ambiental. Curitiba: Ponto Vital Editora, 2015. p. 49-70. 
FIGUEIREDO, F. J. Q. A aprendizagem colaborativa de línguas. Goiânia: Ed. UFG, 2006.

FREIRE, P. A importância do ato de ler: em três artigos que se completam. 23. ed. São Paulo: Cortez, 1989.

. Pedagogia do oprimido. 32. ed. Rio de Janeiro: Paz e Terra, 2002.

GOHN, M. G. Educação não formal e cultura política: impactos sobre o associativismo do terceiro setor. 5. ed. São Paulo: Cortez, 2011.

INSTITUTO JONES DOS SANTOS NEVES. Mapeamento geomorfológico do Estado do Espírito Santo. 19f.: il. (Nota técnica, 28), Vitória, 2012.

JACOBUCCI, D. F. C. Contribuições dos espaços não-formais de educação para a formação da cultura científica. Em extensão, Uberlândia, v. 7, p. 55-66, 2008.

LEONOR, P. B. Ensino por investigação nos anos iniciais: análise de sequências didáticas de ciências sobre seres vivos na perspectiva da alfabetização científica. 2013. 190 f. Dissertação (Mestrado em Educação em Ciências e Matemática) - Instituto Federal de Educação, Ciência e Tecnologia do Espírito Santo, Vitória, 2013.

LÜDKE, M.; ANDRÉ, M. E. D. A. Pesquisas em educação: abordagens qualitativas. São Paulo: EPU, 1986.

MORIN, E. Introdução ao pensamento complexo. 5. ed. Lisboa: Instituto Piaget, 2008.

NEWMAN JÚNIOR, W. J. et al. Dilemmas of teaching inquiry in elementary science methods. Journal of Science Teacher Education, Abingdon, n. 15 v. 4, p. 257-279, 2004.

NUNES, F. C. Grupo Barreiras. Rio de Janeiro: Embrapa Solos, 2011.

PAVANI, E. C. R. Aulas de campo na perspectiva histórico-crítica: contribuições para os espaços de educação não formal. 2013. 110 f. Dissertação (Mestrado em Educação em Ciências e Matemática) - Instituto Federal do Espírito Santo, Vitória, 2013.

PIRANHA, J. M. Interdisciplinaridade no trabalho educacional. In: BACCI, D. L. C. (Org.). Geociências e Educação Ambiental. Curitiba: Ponto Vital Editora, 2015. p. 26-34.

RENDEIRO, M. F. B.; SANTOS JÚNIOR, M. A.; TERÁN, A. F. O uso de trilhas para o ensino de Ciências. In: SIMPÓSIO DE EDUCAÇÃO EM CIÊNCIAS NA AMAZÔNIA, 2., 2012, Manaus. Anais... Manaus: PPGEEC/UEA, set. 2012.

SASSERON, L. H.; CARVALHO, A. M. P. Almejando a alfabetização científica no ensino fundamental: a proposição e a procura de indicadores do processo. Investigações em Ensino de Ciências, Porto Alegre, v. 13, n. 3, p. 333-352, 2008.

SCUDELARI, A. C. et al. Desenvolvimento de um checklist para estudo da erosão costeira em falésias. Revista de Geologia, Fortaleza, v. 20, n. 2, 157-169, 2007. 
SENICIATO, T.; CAVASSAN, O. Afetividade, motivação e construção de conhecimento científico nas aulas desenvolvidas em ambientes naturais. Ciências e Cognição, João Pessoa, v. 13, n. 3, p. 120-136, 2008.

. Aulas de campo em ambientes naturais e aprendizagem em ciências: um estudo com alunos do ensino fundamental. Ciência \& Educação, Bauru, v.10, n.1, p. 133-147, 2004.

SILVA, J. S. R.; SILVA, M. B.; VAREJÃO, J. L. Os (des)caminhos da educação: a importância do trabalho de campo na Geografia. Vértices, Campos dos Goytacazes, v. 12, n. 3 , p. 187-197, set./dez. 2010.

SILVA, M. S. et al. Aula de campo e alfabetização científica em ambientes costeiros: atividades colaborativas nas falésias do sul capixaba. In: ENCONTRO NACIONAL DE PESQUISA EM EDUCAÇÃO EM CIÊNCIAS, 10., 2015, Águas de Lindóia. Anais... Águas de Lindóia: Abrapec, nov. 2015. Disponível em: http:/ /www.xenpec.com.br/ anais2015/busca.htm?query=Marcelo+Scabelo. Acesso em: 16 maio. 2016.

TRILLA, J. A educação não formal. In: ARANTES; V. A. (Org.). Educação formal e não formal. São Paulo: Summus, 2008. p. 15-58.

VIVEIRO, A. A.; DINIZ, R. E. S. Atividades de campo no ensino das ciências e na educação ambiental. Ciência em Tela, Rio de Janeiro, v. 2, n. 1, p. 1-12, 2009.

ZOMPERO, A. F.; LABURU, C. E. Atividades investigativas no ensino de ciências: aspectos históricos e diferentes abordagens. Ensaio, Belo Horizonte, v. 13, n. 3, p. 67-80, set./dez., 2011. 